\title{
A Circumplex Model of the Behavioural Antecedents of Unintended Strategic Alliance Termination: A PLS-based Analysis.
}

\author{
Completed Research Paper
}

\author{
Olivier Furrer \\ University of Fribourg, Switzerland \\ e-mail: olivier.furrer@unifr.ch \\ Jörg Henseler \\ University of Twente, The Netherlands \\ e-mail: j.henseler@utwente.nl
}

\author{
Brian Tjemkes \\ VU University Amsterdam, The Netherlands \\ e-mail: btjemkes@feweb.vu.nl
}

\begin{abstract}
How do firms terminate unsatisfactory strategic alliances? Previous literature on alliance termination has considered exiting an alliance to be a single event. Drawing on circumplex response strategy literature, we propose that alliance termination is part of an integrated system of behavioural responses to adversity. The findings of a scenario-based experiment, obtained through PLS modelling, demonstrate that alliance termination is part of an integrated structure of response strategies governed by two active-passive and constructive-destructive dimensions, which suggests that intermediate behavioural responses precede alliance termination. The article also shows that alliance termination can occur through two alternative termination paths depending on the nature of the adverse situation. Building on these findings, the article concludes with some guidelines for managers confronted with alliance termination.
\end{abstract}

Keywords: Strategic alliances, Circumplex model, Partial least squares, Response strategies. 


\section{Introduction}

In recent decades, strategic alliances have emerged as cornerstones of the competitive strategy of many firms (Kale \& Singh, 2009). However, they also tend to exhibit a mix of promise and peril, resulting in a high termination rate of between 60 and $70 \%$ (Hughes \& Weiss, 2007). Such a high failure rate highlights the need for a better understanding of alliance termination, as unintended dissolution could often be avoided if the managers involved better understood the early warning signals (Ariño \& Doz, 2000).

While there is a large amount of scholarly work on alliance formation and maintenance, little is known about the dissolution of alliances. In particular, studies of how partners exit from alliances are virtually non-existent (for a notable exception, see Alajoutsijärvi et al., 2000). Most scholars consider alliance dissolution to be a natural and unavoidable stage in the life cycle of an alliance and have identified a wide range of environmental, inter-partner, and partner-related factors that influence alliance dissolution (Makino et al., 2007; Park \& Ungson, 2001). Despite such important advances, these alliance termination studies tend to view alliance dissolution as a single event, which they treat as a black box, and neglect the process that leads to dissolution (Halinen \& Tähtinen, 2002). There is a particular dearth of studies on the behaviour of partner firms leading up to termination. A better understanding of behavioural antecedents of alliance dissolution would offer alliance managers the opportunity to react before it is too late.

To fill this void, the present study has drawn on the circumplex response strategy literature (Furrer et al., 2012a, b), which suggests that, in addition to alliance termination (i.e., exit), there are six other response strategies that alliance managers can use to deal with adverse alliance situations: opportunism, aggressive voice, creative voice, considerate voice, patience, and neglect. The study also suggests that the seven response strategies are not independent from each other; instead, they are organised systematically according to their degree of compatibility and incompatibility (Tjemkes et al., 2011). This made it possible to develop and assess a model of alliance termination that proposes two alternative termination trajectories: an active path and a passive path. The model and its predictions are empirically tested with PLS path modelling. In line with the topic of this conference, partial least square (PLS) modelling was used in a novel way to test the structural paths toward exit.

\section{A Circumplex Model of Alliance Termination}

\subsection{Alliance termination}

Alliance termination refers to the dissolution of an alliance resulting from a decision by one or more partners to exit the relationship (Ping, 1999). Although an alliance may also end on a predetermined date or when the partners have realised their objectives, the extant alliance termination studies have considered dissolution to be an unintended event triggered by unanticipated contingencies (Makino et al., 2007). These contingencies span a wide variety of factors, the most critical of which being external environment, partner firm's behaviour, and inter-partner relational outcomes. Studies have shown that changes in a partner firm's behaviour, such as changes in strategic objectives (Harrigan \& Newman, 1990) and knowledge accumulation (Hamel, 1991), can lead to alliance termination. A third stream of research found that premature alliance dissolution can be caused by inter-partner relational outcomes, such as low economic performance poor working relationships (Ariño \& de la Torre, 1998).

Together, these studies have advanced the understanding of why alliance partners 
prematurely terminate their alliance relationships. However, because these studies investigate the factors that influence alliance termination, they consider the termination decision as a single event in the life cycle of an alliance. In doing so, they create a black box around the dissolution process and fail to account for the behaviour of the partners that lead to termination. Consequently, these studies reduce the ability of managers to prevent or manage the dissolution, as they ignore critical early warning signals incorporated in partners' behaviour.

Anecdotal evidence suggests that instead of viewing alliance termination as a single event, it should be seen as a trajectory involving a succession of behavioural responses to adverse contingences. For example, Awazu (2006) found in series of case studies that instead of terminating an alliance immediately, it is better to phase it out by reducing dependency on the alliance and then moving towards termination in graded phases. Lowering the intensity of alliances gives a partner firm an opportunity to reassess its needs and find a new partner to reach its objectives if warranted. To address this issue and identify alternative alliance termination trajectories, we next draw on response strategy literature.

\subsection{Response strategies}

A response strategy is a manager's intended reaction to relationship dissatisfaction (Tjemkes \& Furrer, 2010; Tjemkes et al., 2012). The termination of an alliance and, more particularly, a partner's exit from an alliance, is one of several possible responses to adverse contingencies. Building on the active-passive and constructive-destructive two-dimensional space, Furrer et al. (2012a) demonstrated that a circumplex structure best represents the interrelationships among the seven response strategies. A circumplex structure systematically organises response strategies according to their degree of compatibility and incompatibility (Fabrigar et al., 1997). A total of seven response strategies have been distinguished, and these can be classified according to their degree of activeness-passiveness and constructivenessdestructiveness (Furrer et al., 2012a).

Exit refers to the termination of the current alliance and is the most destructive response to an adverse situation (Rusbult et al., 1982). Opportunism represents an active-destructive response used by alliance partners in an attempt to increase their benefits from the alliance in ways that are explicitly or implicitly prohibited in the alliance contract (Ping, 1993). Considerate voice is a constructive and slightly active response strategy that is used to change an adverse situation by communicating in a relationship-preserving manner and discussing problems cooperatively with once partner (Hagedoorn et al., 1999). Compared to considerate voice, aggressive voice is more destructive and more active. It refers to the forceful imposition of own views on one's partners without making any attempt to avoid conflicts (Hagedoorn et al., 1999). Creative voice refers to the generation of innovative and potentially useful solutions to address the adverse situation (Zhou \& George, 2001), which makes it both active and constructive (Furrer et al., 2012a). Patience refers to the response strategy used by an alliance partner that silently abides the issues in the belief that the situation will improve in the future (Ping, 1993). Patience is both constructive and passive because it involves voluntarily ignoring the issue in the hope that the situation will resolve itself. Finally, neglect is passive but destructive because as the alliance partner allows the relationship to deteriorate (Rusbult et al., 1982). A neglectful alliance manager believes that an alliance does not deserve to be salvaged and expends little effort keeping it afloat (Pressey \& Qu, 2007).

\subsection{Alliance termination paths}

One important implication of the circumplex structure of response strategies is that 
adverse contingencies do not necessarily and immediately lead to alliance termination. The circumplexity of the model allows for two alternatives paths towards exit. The active path towards exit stipulates that exit is associated with a series of anteceding active response strategies of increasing destructiveness: considerate voice, creative voice, aggressive voice and opportunism. In contrast, the passive path towards exit stipulates that exist is associated to a series of anteceding passive response strategies of increasing destructiveness: considerate voice, patience, and neglect.

Hypothesis 1a: Exiting an alliance is associated with a series of increasingly destructive active behaviours in the following order: considerate voice, creative voice, aggressive voice, and opportunism.

Hypothesis 1b: Exiting an alliance is associated with a series of increasingly destructive passive behaviours in the following order: patience and neglect.

The active and passive paths are likely to be triggered by different types of adverse contingencies. Previous studies (e.g., Tjemkes \& Furrer, 2010; Tjemkes et al., 2012) have suggested that economic and social satisfaction, alliance-specific investments, and alternative availability influence the use of active or passive response strategies. Consistent with the investment model (Tjemkes \& Furrer, 2010), social satisfaction, which pertains to the evaluation of the psycho-social aspects of an alliance (Geyskens \& Steenkamp, 2000) and alliance-specific investments, which represent sunk costs that cannot be easily redeployed to another alliance without important costs (Ping, 1993), are likely to trigger the passive path towards exit. The findings of Tjemkes et al. (2012) also suggest that economic satisfaction and alternative availability might influence which termination path would be followed. An economically satisfied manager would consider the alliance to be a success in terms of goal attainment, effectiveness, productivity and the resulting financial outcomes (Geyskens \& Steenkamp, 2000). Therefore, managers who are satisfied with the economic performance of the alliance are more likely to respond with patience (Tjemkes \& Furrer, 2010), which would trigger the passive path towards exit if the adverse situation is not resolved. Alternative availability is the extent to which a partner firm in the alliance possesses attractive alternatives to reach its objectives (Ping, 1993). Firms without alternatives have strong incentives to make the current alliance work and to use considerate voice to improve the situation (Tjemkes \& Furrer, 2010); if the adverse situation is not resolved, this is likely to be the trigger for the active path towards exit.

Hypothesis 2: The active path towards exit is likely to be triggered by (a) financial dissatisfaction and (b) a lack of alternatives.

Hypothesis 3: The passive path towards exit is likely to be triggered by (a) social dissatisfaction and (b) alliance-specific investments.

\section{Data and Methods}

The empirical part of this study uses PLS path modelling first to assess the circumplex structure of alliance termination and then test the structural model of the two paths towards exit. 


\subsection{Study setting and procedure}

To assess the structure and the predictions of the circumplex model of response strategies, a scenario-based experiment was designed with a method that has proven useful for studying response strategies (Rusbult et al., 1988; Tjemkes \& Furrer, 2010). To trigger response strategies, scenarios were developed that described an adverse situation in a strategic alliance between two partner firms. Following the design developed by Tjemkes and Furrer (2010), the scenarios manipulated four exchange variables - economic satisfaction, social satisfaction, alliance-specific investments, and the availability of alternatives at two levels each. The manipulations were combined to form 16 different scenarios and the all-positive scenario was removed because pre-tests indicated that it was not adverse enough to trigger a response.

We used business students as respondents to test the hypotheses. The sample consisted of 336 respondents, 303 of whom delivered complete information. The average age of the respondents was 26.4 years, and 32\% were female. During class hours, students received an invitation to participate in an experiment. Participants in the study were asked to read the scenario and answer the questions as if they were the alliance manager responsible for dealing with the adverse situation.

\subsection{Response strategy measurement}

In order to measure the seven response strategies, the scales developed and validated by Tjemkes and Furrer (2010) were used. Exit was measured with items related to whether the respondent intended to end the relationship or stop doing business with their alliance partner. The measures for opportunism included items such as withholding information, exaggerating the severity of the situation, and escaping from contractual obligations. Aggressive voice items referred to pushing the firm's solution on its partner forcefully and being persistent. For creative voice, the items used related to the creation of novel and creative solutions. To measure considerate voice, the items consisted in working to create a consensus and finding a satisfactory solution acceptable for both partners. Patience was measured with items such as optimistically waiting for better times and trusting that the situation would resolve itself. The items for neglect referred to not dealing with the issue, not putting additional effort into the relationship, and not presenting initiatives to improve the situation. See Appendix A for the complete list of the items. All constructs were operationalised by reflective multi-item measures using seven-point Likert scales, ranging from "I would definitely not react in this way" [1] to "I would definitely react in this way" [7].

\subsection{Exchange variables measures and manipulation checks}

The four exchange variables were measured in order to assess the effects of the scenarios' manipulations. Economic satisfaction represents a partner's evaluation of the financial outcomes of the relationship (Geyskens \& Steenkamp, 2000). Social satisfaction pertains to managers' evaluation of the psycho-social aspects of the relationship; it implies that interactions with partners are fulfilling, gratifying and facile (Geyskens \& Steenkamp, 2000). Alliance-specific investments are sunk costs that cannot be easily redeployed to another relationship without some sacrifice in the productivity of the assets or a cost to adapt them to the new context. When such investments are unilateral and would be lost if the alliance were dissolved, they act as exit barriers. Available alternatives refer to the extent to which a partner firm possesses attractive alternatives that could enable managers to attain their firms' objectives (Ping, 1993, 1999). The availability of attractive alternatives provides managers with a source of power over the situation, whereas a dearth of alternatives increases their 
dependence on counterparts (Emerson, 1962). Exchange variable were measured by multiple items on seven-point Likert scales.

\subsection{Control variables}

Several control variables were measured. Because some response strategies (such as considerate voice) may be more socially desirable than others (such as opportunism), the MC2 version of the Marlowe-Crowne Social Desirability scale was included (Strahan \& Gerbasi, 1972). In addition, the respondents' age and gender was measured because these individual characteristics have been shown to influence response strategies (e.g., Rusbult et al., 1988). In addition, one item was used to assess the perception of the severity of the situation described in the scenario.

\section{Analysis}

\subsection{Measurement model}

The reliability and validity of the construct measurement was assessed based on the recommendations formulated by Hair et al. (2012) and Henseler et al. (2009). The internal consistency reliability was estimated using Cronbach's alpha $(\alpha)$ and Jöreskog's rho $\left(\rho_{c}\right) . \alpha$ is typically a lower bound to reliability, and $\rho_{\mathrm{c}}$, which relies on PLS' upwards-biased construct loadings (Gefen et al., 2011), rather overestimates the reliability. Therefore, the true construct reliability is likely to lie between $\alpha$ and $\rho_{\mathrm{c}}$. Based on reliability considerations, five indicators were discarded (see Appendix A for the list of indicators and their standardised loadings). As shown in the Appendix, all constructs exhibit sufficient levels of internal consistency reliability, passing the conventional threshold of .7 (Nunnally, 1978).

Convergent validity was assessed using the average variance extracted (AVE) method. All AVE values are above the critical value of .5 (Fornell \& Larcker, 1981), which indicates that all constructs are uni-dimensional. The Appendix also shows the AVE values as well as the construct correlations. A comparison of the largest squared construct correlation (that is, .30 between considerate voice and creative voice) with the smallest AVE (.52 of considerate voice) shows that the Fornell-Larcker criterion is met. Therefore, discriminant validity can also be confirmed.

Finally, the experimental manipulations were validated. Bootstrapping was used with 1000 bootstrap samples and the individual sign change option was used to quantify the relationships between the experimental factors and the manipulation check variables. The correlation was determined for all four experimental factors, as was its significance and Cohen's $\mathrm{f}^{2}$ (Cohen, 1988), economic satisfaction $\left(\mathrm{R}=.58, \mathrm{p}<.001, \mathrm{f}^{2}=.51\right)$, social satisfaction $\left(\mathrm{R}=.67, \mathrm{p}<.001, \mathrm{f}^{2}=.81\right)$, alliance-specific investments $(\mathrm{R}=.56, \mathrm{p}<.001$, $\left.\mathrm{f}^{2}=.46\right)$, and availability of attractive alternatives $\left(\mathrm{R}=.64, \mathrm{p}<.001, \mathrm{f}^{2}=.70\right)$. Overall, the experimental manipulations showed adequate performance given that the four experimental factors explained their measured counterparts significantly and substantially.

In order to assess the circumplex structure of response strategies with PLS, the two activepassive and constructive-destructive dimensions of the structure were modelled first, we followed the procedure developed by Furrer et al. (2012b). The two passive-active and constructive-destructive dimensions of the structure were modelled first to assess the circumplex structure of response strategies. An enhanced hierarchical component model (depicted in Appendix B) was estimated to validate these two dimensions, using the repeatedindicator approach (Wetzels et al. 2009; Ringle et al. 2012) in combination with the factor- 
weighting scheme (Lohmöller, 1989). We relied on deflation as a sequential estimation approach (Lohmöller, 1989), which implied two estimation rounds. The first round estimated the loadings of the first dimension of response strategies. The second round used the measurement residuals of the first dimension as indicators for the second component. This makes it possible to identify two orthogonal dimensions.

The hierarchical component model was enhanced by an orthogonal component rotation, including sign constraints. The PLS algorithm ${ }^{1}$ was extended to determine the angle $\varphi$ between the first higher-order dimension and the exit construct. Both higher-order dimensions of response strategies were then orthogonally rotated using the following rotation matrix:

$$
R_{-\varphi}=\left(\begin{array}{cc}
\cos \varphi & \sin \varphi \\
-\sin \varphi & \cos \varphi
\end{array}\right)
$$

Moreover, the first higher-order dimension was multiplied with the sign of the correlation with the exit construct. The second higher-order dimension was multiplied with the sign of the correlation with the aggressive voice construct. This procedure circumvented sign indeterminacy and ensured that the first dimension of the response strategy space (constructive-destructive) was equal to the exit construct, whereas the second dimension represented the passive-active dimension. Table 2 lists the path coefficients of the paths from the two dimensions to the seven response strategies as polar coordinates. For each response strategy, radius $r$ was obtained as the Euclidean distance from the origin

$$
r=\sqrt{b_{1}^{2}+b_{2}^{2}}
$$

where $b_{1}$ is the path coefficient from the constructive-destructive dimension and $b_{2}$ is the path coefficient from the passive-active dimension. The corresponding angle $\varphi\left(0^{\circ} \leq \varphi<360^{\circ}\right)$ was obtained by

$$
\varphi=\operatorname{sgn}\left(b_{2}\right) \cdot\left(\cos ^{-1}\left(b_{1} / r\right)-180^{\circ}\right)+180^{\circ}
$$

\subsection{Structural model results}

The guidelines established by Bagozzi (1977) were followed in order to evaluate the outcomes of the experiment and test Hypothesis 1. Bagozzi suggested that, instead of taking the direct manipulations as the independent variables, it would be preferable to model latent variables as independent variables, which are measured by manipulation checks and influenced by the manipulations. Based on this configuration, the model was estimated as depicted in Figure 1. SmartPLS 2.0 M3 was used (Ringle et al., 2005). To avoid possible problems of non-convergence, the path-weighting scheme was chosen and the factorweighting scheme for triangulation was used (Henseler, 2010). No differences were found. We also applied bootstrapping with 1000 bootstrap samples and the individual sign change option for inference statistics.

The control variables were kept in the model because they had some influence on the endogenous variables. As anticipated, social desirability bias negatively affected opportunism $(\beta=-.072, \mathrm{p}<.10)$; it also stimulated considerate voice $(\beta=.127, \mathrm{p}<.05)$. Severity reduced the respondents' patience $(\beta=-.207, \mathrm{p}<.001)$ and made them more likely to use creative voice $(\beta=.094, \mathrm{p}<.10)$. There were also some effects of age and gender.

The model was able to explain a substantial proportion of variance of the endogenous constructs. Almost half of the variance of the final outcome variable (exit) could be explained

\footnotetext{
We programmed this extension as part of an implementation of the PLS path modeling algorithm in $\mathrm{R}$ 2.14.1 ( $\mathrm{R}$ Development Core Team, 2011). Results obtained by the R-based implementation of the standard PLS algorithm were equal to results obtained by SmartPLS 2.0 M3 (Ringle et al. 2005). The R code is available from the third author upon request.
} 
$\left(\mathrm{R}^{2}=.477\right)$. The other response strategies' coefficients of determination ranged from .047 for aggressive voice to .344 for creative voice. Figure 1 reports all of the $\mathrm{R}^{2}$-values and path coefficient estimates.

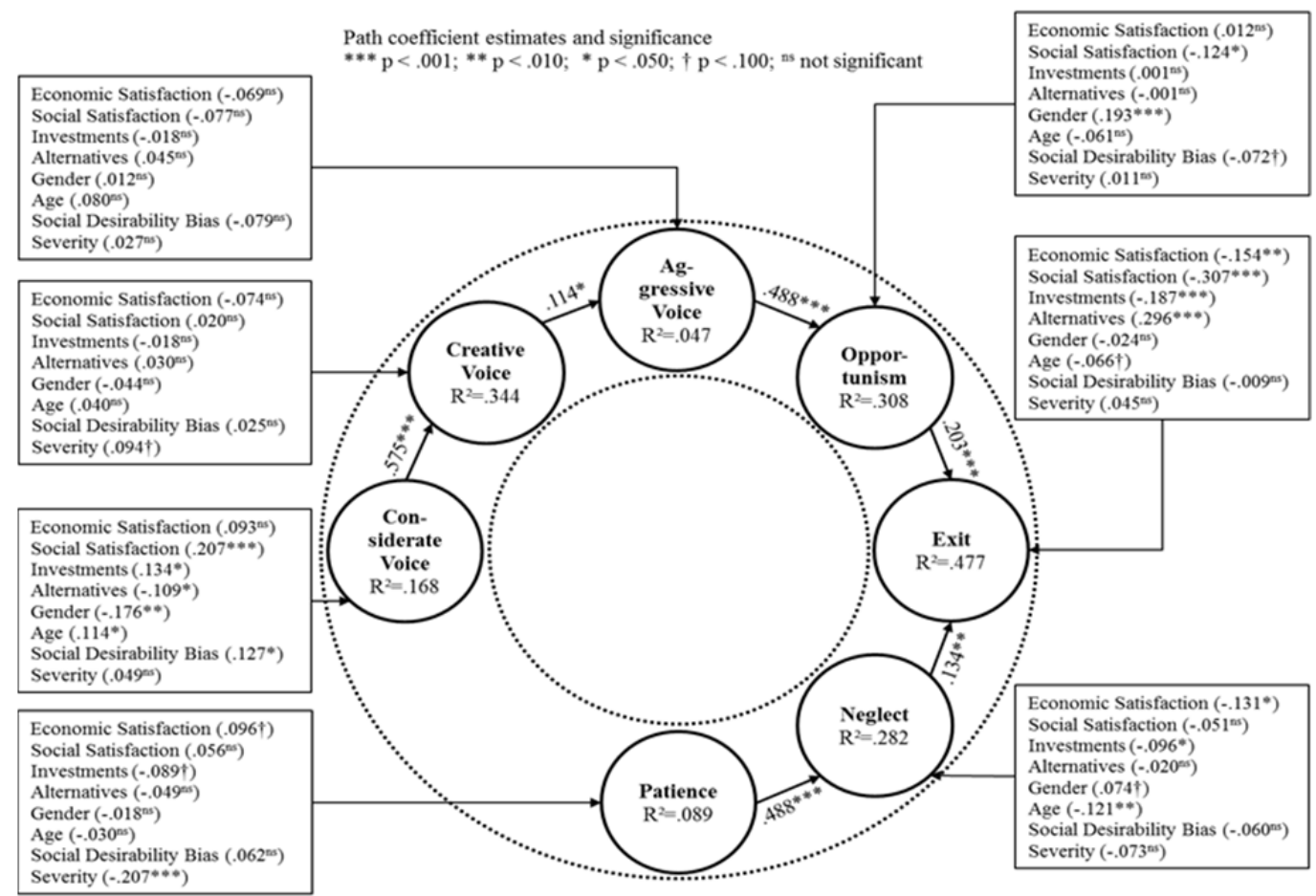

Figure 1: Model Results

The four manipulated exchange variables have different effects on the response strategies. A lack of economic satisfaction leads to neglect $\left(\beta=.131, \mathrm{p}<.05, \mathrm{f}^{2}=.018\right)$ and exit $\left(\beta=.154, \mathrm{p}<.01, \mathrm{f}^{2}=.036\right)$. However, the higher the economic satisfaction, the greater the likelihood that respondents are patient $\left(\beta=.096, \mathrm{p}<.10, \mathrm{f}^{2}=.008\right)$. Social satisfaction stimulates considerate voice $\left(\beta=.207, \mathrm{p}<.001, \mathrm{f}^{2}=.042\right)$ and causes respondents to refrain from opportunism $\left(\beta=-.124, \mathrm{p}<.05, \mathrm{f}^{2}=.016\right)$ and exit $\left(\beta=-.307, \mathrm{p}<.001, \mathrm{f}^{2}=.081\right)$. Large investments make respondents more inclined to use considerate voice $(\beta=.134$, $\left.\mathrm{p}<.05, \mathrm{f}^{2}=.019\right)$; otherwise, patience $\left(\beta=-.089, \mathrm{p}<.10, \mathrm{f}^{2}=.008\right)$, neglect $(\beta=-.096$, $\left.\mathrm{p}<.05, \mathrm{f}^{2}=.013\right)$ and exit $\left(\beta=-.187, \mathrm{p}<.001, \mathrm{f}^{2}=.061\right)$ are less likely. The availability of attractive alternatives has a negative influence on considerate voice $(\beta=-.109, \mathrm{p}<.05$, $\left.\mathrm{f}^{2}=.012\right)$ and makes exit more likely $\left(\beta=.296, \mathrm{p}<.001, \mathrm{f}^{2}=.155\right)$.

As hypothesised, there is empirical support for the existence of two paths towards alliance termination. Exiting an alliance is preceded by a series of increasingly destructive active behaviours. Considerate voice leads to creative voice $\left(\beta=.575, \mathrm{p}<.001, \mathrm{f}^{2}=.413\right)$, creative voice leads to aggressive voice $\left(\beta=.114, \mathrm{p}<.05, \mathrm{f}^{2}=.013\right)$, aggressive voice leads to opportunism $\left(\beta=.488, \mathrm{p}<.001, \mathrm{f}^{2}=.328\right)$, and opportunism ultimately leads to exit $\left(\beta=.203, \mathrm{p}<.001, \mathrm{f}^{2}=.069\right)$. Therefore, Hypothesis $1 \mathrm{a}$ is supported.

Moreover, exiting an alliance is also preceded by a series of increasingly destructive passive behaviours. Patience leads to neglect $\left(\beta=.482, \mathrm{p}<.001, \mathrm{f}^{2}=.292\right)$, and neglect ultimately leads to exit $\left(\beta=.134, \mathrm{p}<.01, \mathrm{f}^{2}=.031\right)$. Therefore, Hypothesis $1 \mathrm{~b}$ is also supported.

\section{Discussion}




\subsection{Managerial implications}

Understanding the trigger factors for exiting, as well as disengagement behavioural paths, is essential in order to avoid the costs and adverse repercussions resulting from alliance failure. Therefore, the findings of this study could help managers anticipate alliance termination, intervene to avoid the premature termination and dissolution of the alliance, or better manage their exit from the alliance. The circumplex model of alliance termination, specifically the compatibilities between response strategies, enables managers to assess the nature of their own and their counterparts' responses. A response to an adverse situation functions as a predictor of a future response, which enables managers to anticipate future behaviours. In other words, opportunism functions as a warning signal for exit, aggressive voice functions as a warning signal for opportunism, creative voice is a warning signal for aggressive voice, and considerate voice is a warning signal for creative voice. Similarly, neglect functions as a warning signal for exit, and patience for neglect. In order to capitalise on these early warning signals and prevent unnecessary evolution towards exit, managers should closely monitor their partners' behaviour and intervene in a timely manner.

Without management intervention, an alliance is likely to head towards exit. Therefore, it is crucial to choose the appropriate lever with which to turn around the active or passive trajectory towards exit. In order to avoid a partner's opportunism turning into exit, managers may invest in building relational quality, install monitoring mechanisms, deploy social sanctions, and require their partner to make alliance-specific investments to reduce opportunism and trigger constructive responses. Similarly, in order to avoid exit and turn neglect into a constructive patient behaviour, managers could erect exit barriers that promote constructive behaviour, and encourage communication that triggers more active responses.

Managers who are dissatisfied with the alliance and are considering terminating the relationship should understand that their response behaviour signals their intentions to their partners. Therefore, to avoid their counterpart locking them in with pre-emptive measures, these managers must plan their exit from the relationship by taking account of the intermediate response strategies. As the active path toward termination is more easily detected, managers might use the passive path to avoid retaliation (Pressey \& Qu, 2007).

\subsection{Methodological implications}

The present paper illustrates how PLS path modelling can be used to assess a multidimensional set of constructs. More specifically, as far as can be ascertained, our study is the first to apply PLS as a means for analysing a circumplex structure. Estimating a hierarchical component model and applying deflation made it possible to extract two dimensions spanning a plain that contained alliance termination and anteceding response strategies. From a methodological viewpoint, this study provides a blueprint for future studies that explore the dimensionality of other complex strategy phenomena.

\subsection{Limitations and future research}

The empirical study has certain limitations. Firstly, the use of an experimental design, which used business students as respondents, increased the internal validity of the results but could also raise questions about external validity. Despite the fact that the results supported the predictions, further studies should conduct survey research in order to validate the results with alliance managers in natural settings.

Secondly, behavioural intentions were measured rather than actual behaviours. Although intentions are not always perfect predictors of behaviour, the approach taken here attempted 
to assess the intensity of the likelihood of response strategies, an objective that is facilitated more readily by measuring behavioural intentions. It would be desirable to have an assessment of the circumplex model of alliance termination with a survey among alliance managers that taps into actual behaviour and the possible effect of adverse contingencies other that inter-partner factors.

\section{Conclusion}

This article has proposed and empirically tested a circumplex model of alliance termination. The article has demonstrated that alliance termination is part of an integrated structure of seven response strategies governed by two active-passive and constructivedimensions, which suggest that intermediate partner firm's behaviour precedes premature alliance termination. Moreover, the article has shown that alliance termination can evolve through two alternative termination paths: an active path and a passive path depending on the nature of the adverse situation. In so doing, the study contributes to the alliance termination literature by answering the question of how partners exit an alliance, compared to the extant alliance research, which has focused mostly on the why question. Consequently, the present study provides valuable guidelines for managers who are confronted with unintended alliance termination.

\section{References}

Alajoutsijärvi, K., Möller, K., Tähtinen, J. (2000). Beautiful exit: how to leave your business partner. European Journal of Marketing 34, 1270-1289.

Ariño, A., de la Torre, J. (1998). Learning from failure: Towards an evolutionary model of collaborative ventures. Organization Science 9, 306-325.

Ariño, A., Doz, Y. (2000). Rescuing troubled alliances... Before it's too late. European Management Journal 18, 173-182.

Awazu, Y. (2006). Managing technology alliances: The case for knowledge management. International Journal of Information Management 26, 484-493.

Bagozzi, R.P. (1977). Structural equation models in experimental research. Journal of Marketing Research 14, 209-226.

Browne, M.W. (1992). Circumplex models for correlation matrices. Psychometrika 57, 469497.

Chin, W.W., Marcolin, B.L., Newsted, P.R. (2003). A partial least squares latent variable modeling approach for measuring interaction effects: results from a Monte Carlo simulation study and an electronic-mail emotion/adoption study. Information Systems Research 14, 189-217.

Cohen, J. (1988). Statistical power analysis for the behavioral sciences $\left(2^{\text {nd }}\right.$ ed.). Hillsdale, NJ: Lawrence Erlbaum Associates.

Emerson, R.M. (1962). Power-dependence relations. American Sociological Review 27, 3141.

Fabrigar, L.R., Visser, P.S., Browne, M.W. (1997). Conceptual and methodological issues in testing the circumplex structure of data in personality and social psychology. Personality and Social Psychology Review 1, 184-203.

Fornell, C., Larcker, D.F. (1981). Evaluating structural equation models with unobservable variables and measurement error. Journal of Marketing Research 18(1), 39-50.

Furrer, O., Tjemkes, B.V., Ulgen Aydinlik, A., Adolfs, K. (2012a). Responding to adverse 
situations within exchange relationships: The cross-cultural validity of a circumplex model. Journal of Cross-Cultural Psychology 43, 943-966.

Furrer, O., Tjemkes, B.V., Henseler, J. (2012b). A model of response strategies in strategic alliances: a PLS analysis of a circumplex structure. Long Range Planning 45, 424450.

Gefen, D., Straub D.W., Boudreau, M.-C. (2000). Structural equation modeling and regression: Guidelines for research practice. Communications of the Association for Information Systems 4(7), 1-77.

Gefen, D., Rigdon, E.E., Straub, D. (2011). An update and extension to SEM guidelines for administrative and social science research. MIS Quarterly 35, iii-xiv.

Geyskens, I., Steenkamp, J.-B.E.M., (2000). Economic and social satisfaction: Measurement and relevance to marketing channel relationships. Journal of Retailing 76, 11-32.

Hagedoorn, M., Yperen, N.W., Van de Vliert, E., Buunk, B.P., (1999). Employees' reactions to problematic events: A circumplex structure of five categories of responses, and the role of job satisfaction. Journal of Organizational Behavior 20, 309-321.

Hair, J.F., Sarstedt, M., Ringle, C.M., Mena, J.A. (2012). An assessment of the use of partial least squares structural equation modeling in marketing research. Journal of the Academy of Marketing Science, in press.

Halinen, A., Tähtinen, J., (2002). A process theory of relationship ending. International Journal of Service Industry Management 13, 163-180.

Hamel, G, (1991). Competition for competence and interpartner learning within international strategic alliances. Strategic Management Journal 12(SI), 83-103.

Harrigan, K.R., Newman, W.H. (1990). Bases of interorganizational cooperation: Propensity, power, persistance. Journal of Management Studies 27, 417-434.

Henseler, J. (2010). On the convergence of the partial least squares path modeling algorithm. Computational Statistics 25, 107-120.

Henseler, J., Chin, W.W. (2010). A comparison of approaches for the analysis of interaction effects between latent variables using partial least squares path modeling. Structural Equation Modeling 17, 82-109.

Henseler, J., Ringle, C.M., Sinkovics, R.R. (2009). The use of partial least squares path modeling in international marketing. Advances in International Marketing 20, 277319.

Hughes, J., Weiss, J. (2007). Simple rules for making alliances work. Harvard Business Review 85, 122-131.

Hulland, J. (1999). Use of partial least squares (PLS) in strategic management research: a review of four recent studies. Strategic Management Journal 20, 195-204.

Kale, P., Singh, H. (2009). Managing strategic alliances: What do we know now, and where do we go from here? Academy of Management Perspectives 23, 45-62.

Lohmöller, J.-B. (1989). Latent variable path modeling with partial least squares. Heidelberg: Physica.

Makino S., Beamish P.W. (1998). Performance and survival of international joint ventures with nonconventional ownership structures. Journal of International Business Studies 29, 797-818.

Makino, S., Chan, C.M., Isobe, T., Beamish, P.W. (2007). Intended and unintended termination of international joint ventures. Strategic Management Journal 28, 11131132 .

Nunnally, J.C. (1978). Psychometric Theory, $2^{\text {nd }}$ ed. New York et al.: McGraw-Hill.

Park, S.H., Ungson, G.R. (2001). Interfirm rivalry and managerial complexity: A conceptual framework of alliance failure. Organization Science 12, 37-53.

Ping, R.A., (1993). The effects of satisfaction and structural constraints on retailer exiting, 
voice, loyalty, opportunism, and neglect. Journal of Retailing 69, 320-352.

Ping, R.A. (1999). Unexplored antecedents of exiting in a marketing channel. Journal of Retailing 75, 218-241.

Pressey, A.D., Qu, X.X., (2007). Buyer-supplier relationship dissolution: The Chinese context. Journal of Business \& Industrial Marketing 69, 320-352.

Reinartz, W.J., Haenlein, M., Henseler, J. (2009). An empirical comparison of the efficacy of covariance-based and variance-based SEM. International Journal of Market Research $26,332-344$.

Ring, P.S., Van de Ven, A.H. (1994). Developmental processes of cooperative interorganizational relationships. Academy of Management Review 19, 90-118.

Ringle, C., Wende, S., Will, A. (2005). SmartPLS 2.0 (Beta). Hamburg, www.smartpls.de.

Rosse, J. (1988). Relations among lateness, absence and turnover: Is there a progression of withdrawal? Human Relations 41, 517-531.

Rusbult, C.E., Farrell, D., Rogers, G., Mainous, A.G., (1988). Impact of exchange variables on exit, voice, loyalty, and neglect: An integrative model of responses to declining job satisfaction. Academy of Management Journal 31, 599-627.

Rusbult, C.E., Zembrodt, I.M., Gunn, L.K. (1982). Exit, voice, loyalty, and neglect: Responses to dissatisfaction in romantic involvements. Journal of Personality and Social Psychology 43, 1230-1242.

Strahan, R., Gerbasi, K.C., (1972). Short, homogeneous versions of Marlow-Crowne social desirability scale. Journal of Clinical Psychology 28, 191-193.

Tjemkes, B., Furrer, O. (2010). The antecedents of response strategies in strategic alliances. Management Decision 48, 1103-1133.

Tjemkes, B., Furrer, O. (2011). Behavioral responses to adverse situations in strategic alliances, In Behavioral Perspectives on Strategic Alliances, T.K. Das (ed.), Research in Strategic Alliance Book Series, Information Age Publishing, Chapter 10, pp. 227249 , in press.

Tjemkes, B.V., Furrer, O., Adolfs, K., Ulgen Aydinlik, A. (2012). Response strategies in an international strategic alliance experimental context: Cross-country differences, Journal of International Management 18, 66-84.

Wetzels, M., Oderkerken-Schröder, G., van Oppen, C. (2009). Using PLS path modeling for assessing hierarchical construct models: guidelines and empirical illustration. MIS Quarterly 33, 177-195.

Withey, M.J., Cooper, W.H., (1989). Predicting exit, voice, loyalty, and neglect. Administrative Science Quarterly 34, 521-539.

Zhou, J., George, J.M., (2001). When job dissatisfaction leads to creativity: Encouraging the expression of voice. Academy of Management Journal 44, 682-697. 
Appendix: Descriptive Statistics and Correlation Matrix

\begin{tabular}{|c|c|c|c|c|c|c|c|c|c|c|c|c|c|c|c|c|c|c|c|c|c|}
\hline \multicolumn{2}{|c|}{ Variable } & \multirow{2}{*}{$\begin{array}{l}\text { Mean } \\
3.99\end{array}$} & \multirow{2}{*}{$\begin{array}{r}\text { SD } \\
1.42\end{array}$} & \multirow{2}{*}{$\begin{array}{c}\text { Items } \\
2\end{array}$} & \multirow{2}{*}{$\begin{array}{r}\boldsymbol{\alpha} \\
.83\end{array}$} & \multirow{2}{*}{$\begin{array}{c}\boldsymbol{\rho}_{\mathbf{c}} \\
.92\end{array}$} & \multirow{2}{*}{$\frac{\text { AVE }}{.85}$} & \multirow[t]{2}{*}{1} & \multirow[t]{2}{*}{2} & \multirow[t]{2}{*}{3} & \multirow[t]{2}{*}{4} & \multirow[t]{2}{*}{5} & \multirow[t]{2}{*}{6} & \multirow[t]{2}{*}{7} & \multirow[t]{2}{*}{8} & \multirow[t]{2}{*}{9} & \multirow[t]{2}{*}{10} & \multirow[t]{2}{*}{11} & \multirow[t]{2}{*}{12} & \multirow[t]{2}{*}{13} & \multirow[t]{2}{*}{14} \\
\hline 1 & Economic satisfaction & & & & & & & & & & & & & & & & & & & & \\
\hline 2 & Social satisfaction & 4.28 & 1.30 & 3 & .80 & .88 & .72 & .41 & & & & & & & & & & & & & \\
\hline 3 & Investments & 3.41 & 1.55 & 3 & .82 & .92 & .85 & -.13 & -.07 & & & & & & & & & & & & \\
\hline 4 & Alternatives & 4.65 & 1.29 & 3 & .66 & .84 & .73 & -.07 & -.01 & .27 & & & & & & & & & & & \\
\hline 5 & Exit & 3.14 & 1.38 & 5 & .92 & .94 & .76 & -.37 & -.44 & .33 & .35 & & & & & & & & & & \\
\hline 6 & Opportunism & 3.45 & 1.07 & 5 & .78 & .85 & .53 & -.10 & -.16 & .04 & .04 & .31 & & & & & & & & & \\
\hline 7 & Aggressive voice & 4.55 & 1.07 & 3 & .75 & .86 & .66 & -.11 & -.10 & .04 & .07 & .21 & .50 & & & & & & & & \\
\hline 8 & Creative voice & 5.60 & .78 & 5 & .81 & .87 & .58 & .02 & .12 & -.07 & -.03 & -.27 & -.06 & .09 & & & & & & & \\
\hline 9 & Considerate voice & 5.49 & .84 & 5 & .77 & .85 & .52 & .19 & .25 & -.20 & -.15 & -.50 & -.20 & .00 & .55 & & & & & & \\
\hline 10 & Patience & 1.95 & .76 & 4 & .70 & .82 & .53 & .18 & .14 & .04 & -.06 & -.02 & .11 & -.04 & -.19 & -.01 & & & & & \\
\hline 11 & Neglect & 2.11 & .88 & 3 & .68 & .82 & .60 & -.06 & -.03 & .12 & -.03 & .21 & .19 & .04 & -.37 & -.25 & .46 & & & & \\
\hline 12 & Age & 26.37 & 2.92 & 1 & n.a. & n.a. & n.a. & .04 & .08 & .04 & .05 & -.09 & .00 & .09 & .09 & .09 & -.02 & -.13 & & & \\
\hline 13 & Gender & 1.68 & .47 & 1 & n.a. & n.a. & n.a. & .04 & .06 & .04 & .01 & -.01 & .18 & .00 & -.13 & -.15 & -.02 & .04 & .15 & & \\
\hline 14 & Problem severity & 4.56 & 1.42 & 1 & n.a. & n.a. & n.a. & -.31 & -.25 & .07 & .10 & .21 & .08 & .09 & .08 & -.05 & -.25 & -.13 & .03 & .01 & \\
\hline 15 & Social desirability & 5.60 & 2.01 & 10 & n.a. & n.a. & n.a. & .07 & .04 & -.05 & -.08 & -.10 & -.12 & -.08 & .11 & .16 & .08 & -.03 & .01 & .00 & -.02 \\
\hline
\end{tabular}

Notes: $n=303$. Correlations with absolute value greater than .11 are significant at $5 \%$. 